\title{
1 Title: Duckweed roots are dispensable and are on a trajectory toward vestigiality
}

2

4

6

7

8

9

10

11

12

13

14

15

16

17

18

19

20

21

22

\section{Short title: Structural and functional reduction of duckweed roots}

Alex Ware ${ }^{1 *}$, Dylan H Jones ${ }^{1 *}$, Paulina Flis ${ }^{1,2}$, Kellie Smith ${ }^{2,3}$, Britta Kümpers ${ }^{1}$, Levi Yant ${ }^{2,3}$, Jonathan A Atkinson, Darren M Wells and Anthony Bishopp ${ }^{1}$

* These authors contributed equally

${ }^{1}$ School of Biosciences, University of Nottingham, Sutton Bonington Campus, Loughborough, LE12 5RD, UK

2 Future Food Beacon, University of Nottingham, Sutton Bonington Campus, Loughborough, LE12 5RD, UK ${ }^{3}$ School of Life Sciences, University of Nottingham, University Park Campus, Nottingham, NG7 2RD, UK

\section{Author contributions}

$A W, B M K \& A B$ designed the concept. $A W$ and $D J$ performed anatomical analyses and monitored root function with support from JA. PF performed the ionomic profiling. KES aided with sampling for ionomics. $A W \& A B$ wrote the manuscript, with input from all authors.

\section{Acknowledgements}

We acknowledge the Nottingham Future Food Beacon for support with ionomics, and Walter Lämmler from the Landolt Duckweed Collection and Klaus J Appenroth from the Friedrich Schiller University for kindly supplying material used in this study.

One sentence summary: Through their adaption to the aquatic environment, duckweed roots have progressively become structurally reduced making them an ideal plant model with which to study vestigiality.

\section{Funding:}

This work was funded by a Research Project Grant from the Leverhulme Trust (RPG-2018-403). DJ and KES are funded by through the Biotechnology and Biological Sciences Research Council (BB/M008770/1). 


\section{Abstract}

38

39

Duckweeds are morphologically simplified, free floating aquatic monocots comprising both rooted and rootless genera. This has led to the idea that roots in these species may be vestigial, but empirical evidence supporting this is lacking. Here we show that duckweed roots are no longer required for their ancestral role of nutrient uptake. Comparative analyses of nearly all rooted duckweed species revealed a highly reduced anatomy, with greater simplification in the more recently diverged genus Lemna. A series of root excision experiments demonstrated that roots are dispensable for normal growth in Spirodela polyrhiza and Lemna minor. Furthermore, ionomic analyses of fronds in these two species showed little difference in the elemental composition of plants in rooted versus root-excised samples. In comparison, another free-floating member of the Araceae, Pistia stratiotes, which colonized the aquatic environment independently of duckweeds, has retained a more complex root anatomy. Whilst Pistia roots were not absolutely required for growth, their removal inhibited plant growth and resulted in a broad change in the mineral profile of aerial tissues. Collectively, these observations suggest that duckweeds and Pistia may be different stages along a trajectory towards root vestigialization Given this, along with the striking diversity of root phenotypes, culminating in total loss in the most derived species, we propose that duckweed roots are a powerful system with which to understand organ loss and vestigiality.

\section{Introduction}

Evolution has shaped the body plans of all organisms into the myriad of diverse forms we see today. While evolution is commonly envisioned as constantly generating novel forms, things sometimes go the other way: occasionally, entire structures or traits are lost, becoming vestigial. This can result in radical shifts in body plan and life-history strategy and is a key evolutionary process driving structural innovation. Based on earlier definitions (Prout, 1964, Fong et al., 1995, Müller, 2002), vestigiality can be broadly defined as the retention, through evolution, of genetically determined structures that have lost some or all of their ancestral function.

Vestigiality is phylogenetically widespread in plants (Knobloch, 1951). Examples include loss of entire organs, such as floral organs in Penstemon sp., oil glands in Ceratandra flowers, leaf reduction in Equisetum, and non-functional roots in dodder seedlings, and are often concurrent with atypical, innovative body plans or unusual life history strategies (Walker-Larsen and Harder, 2001; Sherman et al., 2008; Steiner, 1998). To date, reports exploring vestigiality in plants are largely descriptive. 
70 Progress into understanding the molecular and evolutionary processes which drive organ loss in 71 plants has therefore been limited.

73 The most advanced work driving our understanding of the molecular control of vestigiality comes 74 from outside the plant kingdom. Perhaps the most detailed work has been done on the blind 75 cavefish, Astyanax mexicanus, where the mechanisms underpinning eye-loss have been well 76 described. Comparisons between blind and sighted cavefish has revealed that lens apoptosis is 77 mediated by expansion of the expression domain of sonic hedgehog $A$ and $B$ ( $\operatorname{shh} A$ and $\operatorname{ssh} B$ ), which 78 negatively regulate the homeobox gene pax6, itself a key regulator of eye development in 79 vertebrates (Yamamoto et al., 2004). It is clear from work in Astyanax that leveraging the presence 80 and absence of organs in closely related species is crucial to gaining an understanding of vestigiality 81 at a molecular level. We propose that root loss in duckweeds represents a powerful untapped model 82 for understanding organ loss in plants due to the existence of closely related rooted and rootless species. Recent development of genetic tools (Yang et al., 2018; Vu et al., 2020; reviewed in Acosta et al., 2021) has enabled exploration of molecular networks in duckweeds. However, any study of vestigiality first requires a detailed understanding of how the organ in question functions. As roots are still retained in many duckweed species, we need clarity on duckweed root function to frame the evolutionary context of this model. Within the literature there are several observations regarding the function of duckweed roots; however there is no single study bringing together multiple lines of empirical evidence supporting their vestigiality.

91 Duckweeds are highly morphologically reduced free-floating angiosperms lacking many of the key 92 organs common in flowering plants, such as clearly defined stems and leaves. The plant body is reduced to a flattened frond or thallus. They comprise five genera divided into two subgroups, Lemnoideae (Spirodela, Landoltia and Lemna) and Wolffioideae (Wolffia and Wolffiela). Within these genera, there is an evolutionary trajectory in root number consistent with root vestigialization: the earliest-diverging duckweed genera (Spirodela and Landoltia) possess multiple roots, later diverging ones a single root (Lemna), and the most recently diverging lineages possess no roots at all (Wollfia and Wolffiela) (Tippery and Les, 2020, Figure 1).

100 Duckweed roots are adventitious and neither branch nor form root hairs (Landolt, 1998). Previous 101 studies have performed detailed investigations into root anatomy in individual species, reporting 102 high levels of structural reduction. Spirodela polyrhiza roots have a stele comprising of one xylem 103 cell, two sieve elements and between five and six phloem parenchyma cells (Kim, 2007). These are 


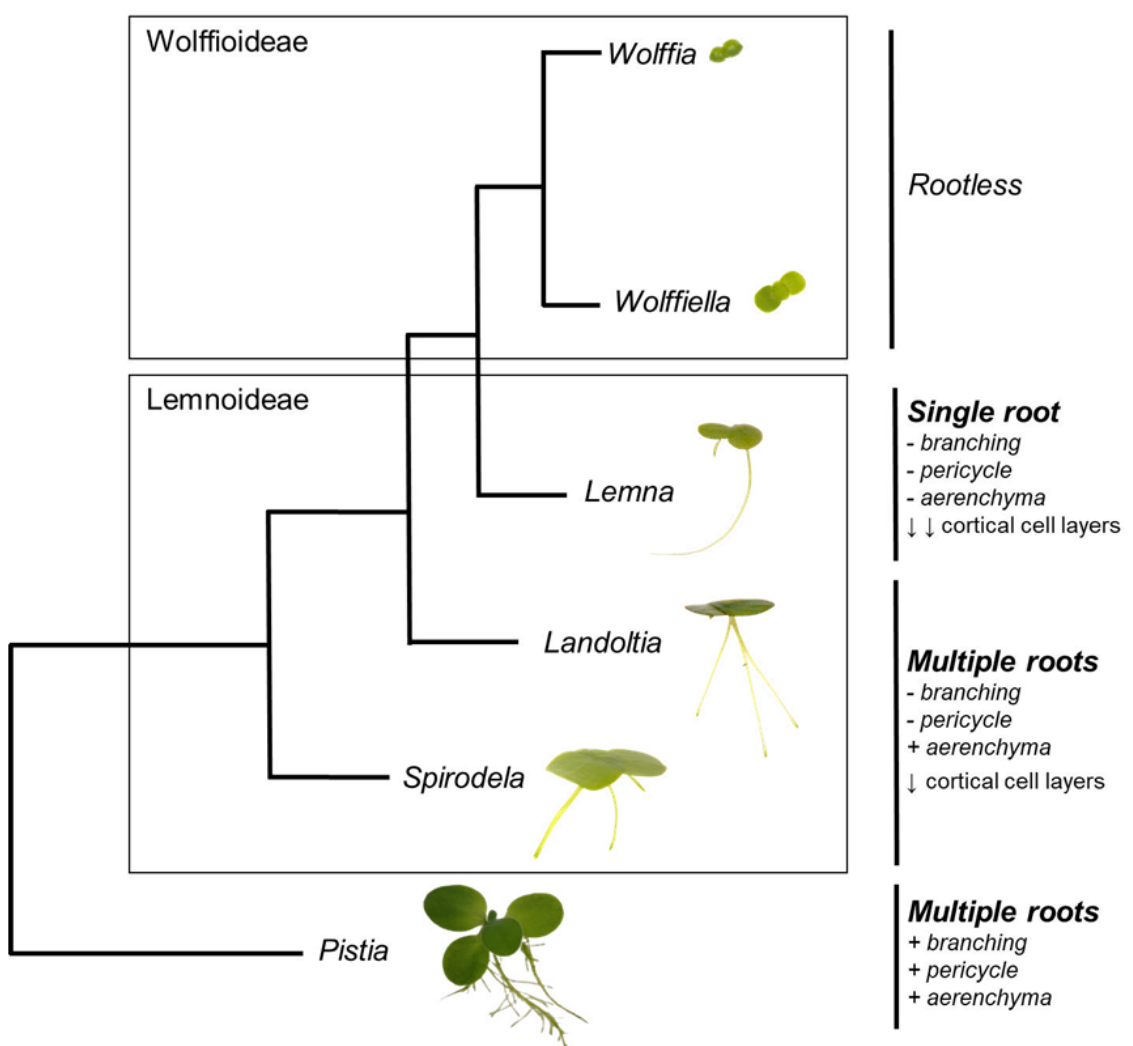

104 enclosed by a single layer of endodermis, three distinct cortical cell layers and between 38-45

105 epidermal cells (Kim, 2007). A similar pattern is reported for Lemna minor (Echlin, 1981). Although

106 there have been other studies of root anatomy (eg. Hegelmaier, 1868), we currently miss a

107 systematic understanding of root anatomy across the three root-bearing genera.

109 Vestigialization not only affects anatomy, but also function. It does not imply that organs should 110 possess no function, only that the salient function is lost. Here, we define the salient function of 111 roots as organs with which to acquire water and nutrients. Various lines of evidence have been 112 presented to support the view that duckweed roots have at most a limited role in nutrient uptake. 113 Hegelmaier (1868) noted that in their natural habitat, individuals of Lemna gibba without roots 114 occur. Gorham (1941) concluded that nutrients were taken up via fronds and not roots, as coating 115 the underside of fronds with a hydrophobic wax reduced the division rate of fronds and caused root 116 elongation, whilst coating the upper surface did neither. Muhonen and colleagues (1983) also noted 117 that Spirodela polyrhiza grew without roots. Whilst these studies suggest that roots may not be 118 required for growth, they do not rule out that duckweed roots still play some role in resource 119 capture. Indeed, it has been observed that both roots and fronds can assimilate nitrogen in both 120 Lemna minor and Landoltia punctata (Cedergreen and Madsen, 2002; Fang et al., 2007). 
122 The above presents an incomplete picture of vestigiality in duckweed roots. To address this, we

123 conducted a survey of duckweed root anatomy across almost all the rooted duckweed species. We

124 examine to what extent changes in anatomy are consistent with roots being vestigial, and if

125 additional structural reduction accompanies the reduction in root number between genera. We then

126 investigated root function in two species by looking at growth and uptake of 13 elements in plants

127 with and without roots excised. By comparing duckweeds with the related free-floating macrophyte

128 Pistia stratiotes we present a scenario in which both anatomical complexity and the role of the root

129 in foraging for nutrients has been progressively lost in duckweeds.

130

131 


\section{Results}

133

134

135

136

137

138

139

140

141

142

143

144

145

146

147

148

149

150

151

152

153

154

155

156

157

158

159

160

161

162

163

164

165

\section{Duckweed root anatomy is highly reduced}

Previous reports of duckweed root anatomy focused on just a few species and have not directly compared these with relatives. Without outgroups, it is impossible to determine if there is a trajectory towards structural reduction in duckweeds. Previous phylogenetic studies have included Pistia stratiotes as an outgroup as another aquatic member of the Araceae (Les et al., 2002). Pistia and duckweeds share several morphological and ecological similarities as free-floating macrophytes but represent independent aroid lineages (Stockey et al., 1997, Wilde et al., 2005). Indeed, both fossil evidence (Stockey et al., 1997, Wilde et al., 2005) and phylogenetic analyses (Friis et al., 2004) suggest that duckweeds and Pistia independently colonized aquatic habitats, with fossils attributable to the duckweeds being much older than those attributable to Pistia (Cabrera et al., 2008). Thus, Pistia provides a useful model for understanding the highly reduced structure in duckweeds as its form resembles ancient fossil duckweeds such as Limnobiophyllum.

We surveyed macroscopic root structure for 20 duckweed lines, representing 13 species, with all Spirodela and Landoltia species represented and 10 of the 13 Lemna species, alongside Pistia stratiotes. Most species were represented by multiple accessions. In no instances were lateral roots or root hairs observed in duckweeds, in line with previous observations (Landolt, 1986). Pistia had a considerably larger and more complex root system with lateral roots. 11 out of 12 duckweeds have a mean root diameter between 120-200 $\mu \mathrm{m}$, with only Lemna yungensis falling outside of this range of means, possessing a mean diameter of $256 \mu \mathrm{m}$. No duckweed species possessed a maximum root diameter close to the $325 \mu \mathrm{m}$ that we observed in Pistia. We counted an average of 212 total cells in Pistia cross-sections, while duckweeds display mean total cells values of 28-81 cells. Spirodela sp. displayed mean cross section cell numbers ranging from 40 to 81 cells. Lemna species typically displayed fewer cells in cross-section than Spirodela; mean values for all species are between 28 and 45 cells, apart from Lemna yungensis, which displays 73. Morphological analysis of root patterning revealed a highly reduced anatomy common to all duckweed species. This consisted of a 3-5 of cortical cell layers and a highly reduced vasculature (Figure 2A). All the duckweed species possessed a single central xylem, typically surrounded by a small number (7-10) of what appear to be phloem parenchyma cells, although this identity has never been explicitly defined. Pistia, conversely, has multiple xylem files and considerably more phloem cells. It also has a discernible pericycle, which was absent in all duckweeds surveyed here (Figure 2A, Figure 3, Supplementary Figure 2). 
bioRxiv preprint doi: https://doi.org/10.1101/2022.01.05.475062; this version posted January 7, 2022. The copyright holder for this preprint (which was not certified by peer review) is the author/funder, who has granted bioRxiv a license to display the preprint in perpetuity. It is made available under aCC-BY-NC-ND 4.0 International license.
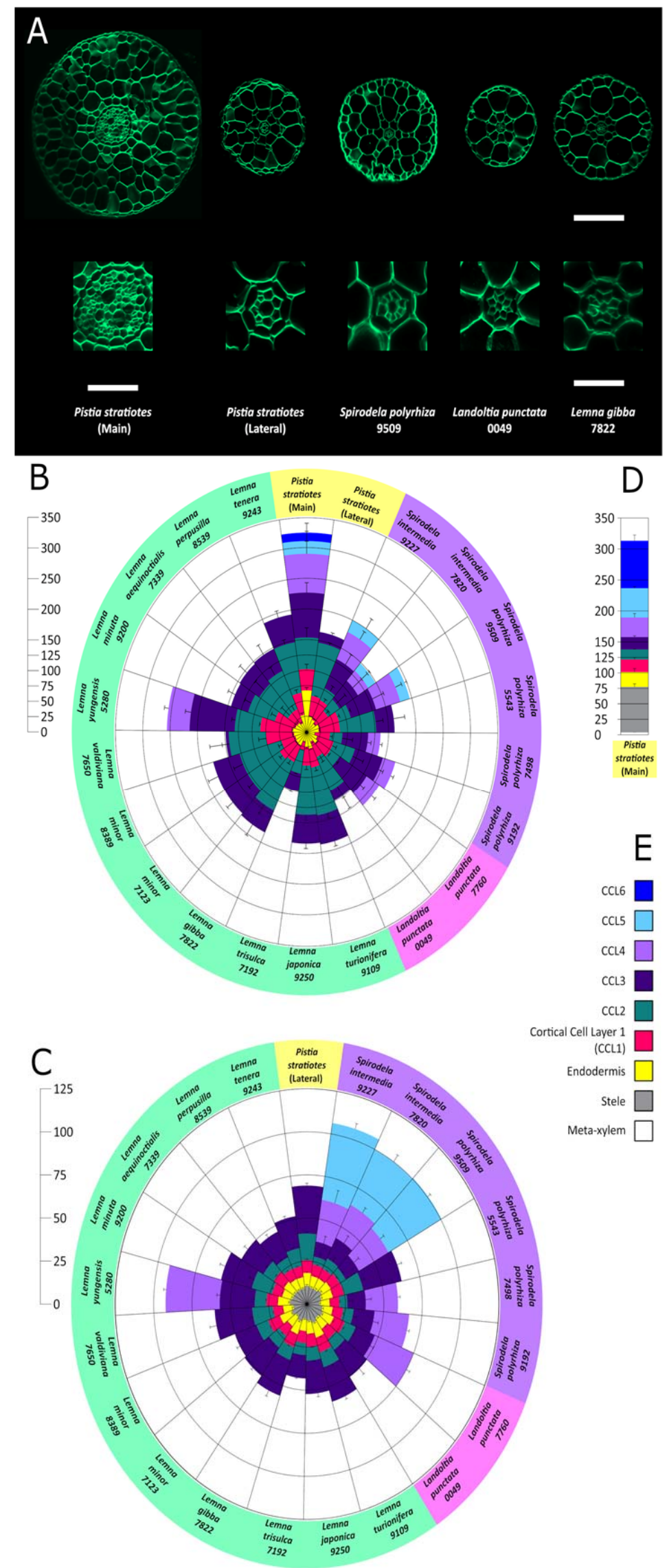

cc16

ccls

CCL4

CCL3

$\mathrm{CCL}_{2}$

Cortical Cell Layer 1

(CC11)

Endodermis

stele $\square$

Meta-xylem 


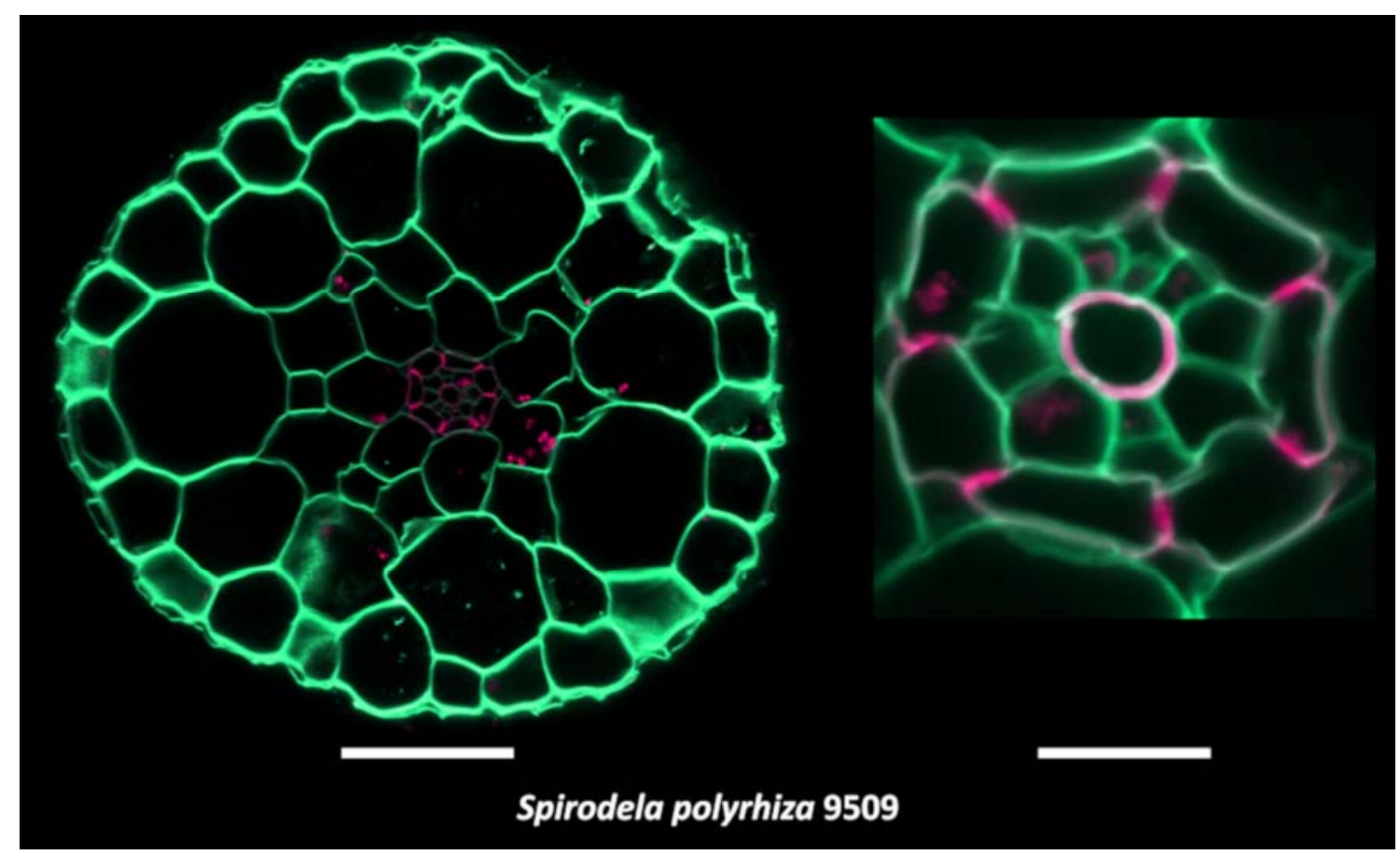

167

We observed a trend in the reduction of number of cortical cell layers (CCLs) from the earlier diverging Spirodela ( 3 of 6 accessions display 5 CCLs) to the later diverging Lemna (3 CCLs in 11 out of 12 accessions) (Figure 2B). This trend is not reflected in the root diameter (Figure 2C). Several duckweed species have large extracellular air spaces within the cortex, similar to the schizogenous aerenchyma found in many other aquatic plants (Jung et al., 2008). This feature appears more frequently in Spirodela (5 out of 6 lines), in 1 out of 2 of the Landoltia lines, and in only 2 out of 12 closely related Lemna lines that are currently proposed to represent a single species (yungensis valdiviana) (Bog et al., 2020) (Figure 2A, Supplementary Figure 1).

Compared with Pistia, the cell number and size of the stele and endodermis is uniformly low across all duckweed species. The total number of cells enclosed by and including the endodermis is remarkably invariable across duckweed species, with all duckweed species falling within the range of 16-18 cells, compared to approximately 100 in Pistia. The diameter of the endodermis is slightly more variable than cell number, with the mean for all species within a range of $15-28 \mu \mathrm{m}$, with no clear pattern between genera. The fact that duckweeds consistently showed reduced cell size and number within the stele suggests reduced importance for transport within the root, consistent with vestigiality.

We quantified a number of parameters relating to number and size of each cell type in the root and conducted a principal coordinates analysis to survey the general trends in this anatomical dataset (Figure 4). Each point represents the data captured from a root section of a separate individual 


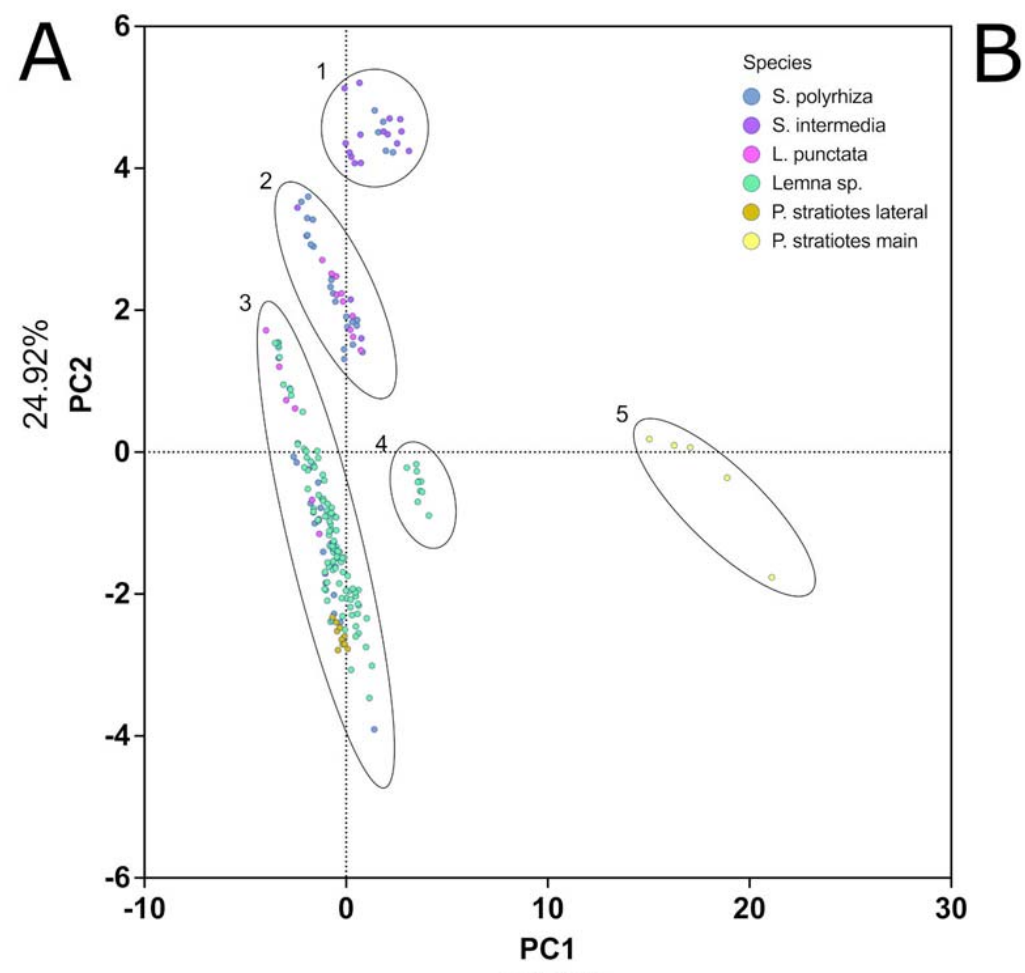

Endodermis diameter

Cell layer 1 diameter

Cell layer 2 diameter

Cell layer 3 diameter

Cell layer 4 diameter

Cell layer 5 diameter

Max. diameter

Max. area

Cortex area

Cells in cortex

Cell layer number

Xylem cell no.

Endodermal cell no.

Phloem/cambial cell no.

Cell layer 1 no.

Cell layer 2 no.

Cell layer 3 no.

Cell layer 4 no.

Cell layer 5 no.

$53.25 \%$

188 (Figure 4A), and the 19 variables are shown in (Figure 4B). The PCoA displays 5 distinct clusters, consistent with phylogenetic groupings. All Lemna species are retained in a single cluster (3), apart from Lemna yungensis, which forms a distinct unique cluster outside of the larger Lemna cluster containing this species alone (4). Spirodela intermedia occurs in two distinct clusters (1 and 2), neither of which contain any Lemna individuals. The majority of Spirodela intermedia individuals cluster together, in a group also consisting of a small number of Spirodela polyrhiza samples (cluster 2). Spirodela polyrhiza is distributed more broadly and located within clusters 1,2 and 3 , with the majority of individuals falling into cluster 2, which contains only Spirodela and Landoltia species. A small number of Spirodela polyhriza samples also fall into the Lemna cluster. Landoltia primarily cooccurs with Spirodela polyrhiza and intermedia in cluster 2, and a few individuals occur in the Lemna cluster. Pistia main roots group distant from all duckweeds driving the main axis, PC1. Interestingly, all Pistia lateral roots fall within the Lemna cluster. Given that the duckweed genera broadly cluster within their own groups, and that we see a reduction in root complexity (CCLs \& aerenchyma) from Spirodela to Lemna, we propose that root anatomy is progressively reduced in more recently derived duckweed lineages. 
We hypothesised that a reduction in root complexity would be reflected by reduced requirement of roots for plant growth. To test this hypothesis, we conducted root removal experiments and compared the growth rate response to root removal in two representative duckweed species, Lemna minor and Spirodela polyrhiza, alongside Pistia stratiotes. Root removal was conducted daily for a period of 11 days to minimise growth of new root material. Growth (as frond or aerial tissue area) was measured daily, normalised as a percent of the initial area value (Figure 5). During the growth series, we observed an approximate 12 fold increase in frond area for Lemna minor, a 10 fold increase for Spirodela polyrhiza, and an 8 fold increase in area for Pistia stratiotes for individuals in control samples where roots were intact (Figure 5). For Spirodela polyrhiza (Figure 5A) we saw no significant difference in growth for rooted versus root-excised samples. In Lemna minor, the only significant differences in growth arose on the final three days of the growth series, where plants with their roots removed displayed enhanced growth (Figure 5B). In contrast, root removal markedly reduced the growth rate of Pistia stratiotes (Figure 5C). These results indicate that duckweed roots are not required to sustain growth in laboratory conditions. These results also suggest that the root is not an essential means of water absorption in duckweed.

Root removal does not impair the ability of Lemna minor or Spirodela polyrhiza to absorb macroand micronutrients, but does impact nutrient uptake in Pistia stratiotes.

The growth rate assay established that rooted versus root-excised duckweeds grew in a similar manner, but root removal impeded the growth of Pistia stratoites. We reasoned that if roots were required for the uptake of specific elements, assays in which we measure specific elements would be more sensitive than a crude measurement of growth in detecting the extent to which roots are still required for their ancestral function. To investigate this, we subjected the fronds and aerial tissues of Pistia generated by the previous experiment to an ionomic analysis. A total of 16 elements were successfully detected in these species. Whilst some rare elements such as $\mathrm{Li}$ and $\mathrm{Cd}$ were detected, we only considered 13 elements present in our growth media $\mathrm{B}, \mathrm{Na}, \mathrm{Mg}, \mathrm{P}, \mathrm{S}, \mathrm{K}, \mathrm{Ca}, \mathrm{Fe}, \mathrm{Mn}, \mathrm{Co}, \mathrm{Cu}$, Zn and Mo (supplementary figure 2). As our analysis was run under atmospheric conditions, we were unable to measure the levels of $\mathrm{N}$.

Root removal in duckweed made little change to the overall accumulation of nutrients in duckweed (Figure 6A, B). Between Lemna minor and Spirodela polyrhiza, there were five instances where root removal significantly altered elemental concentration in the frond. In three instances, root removal 

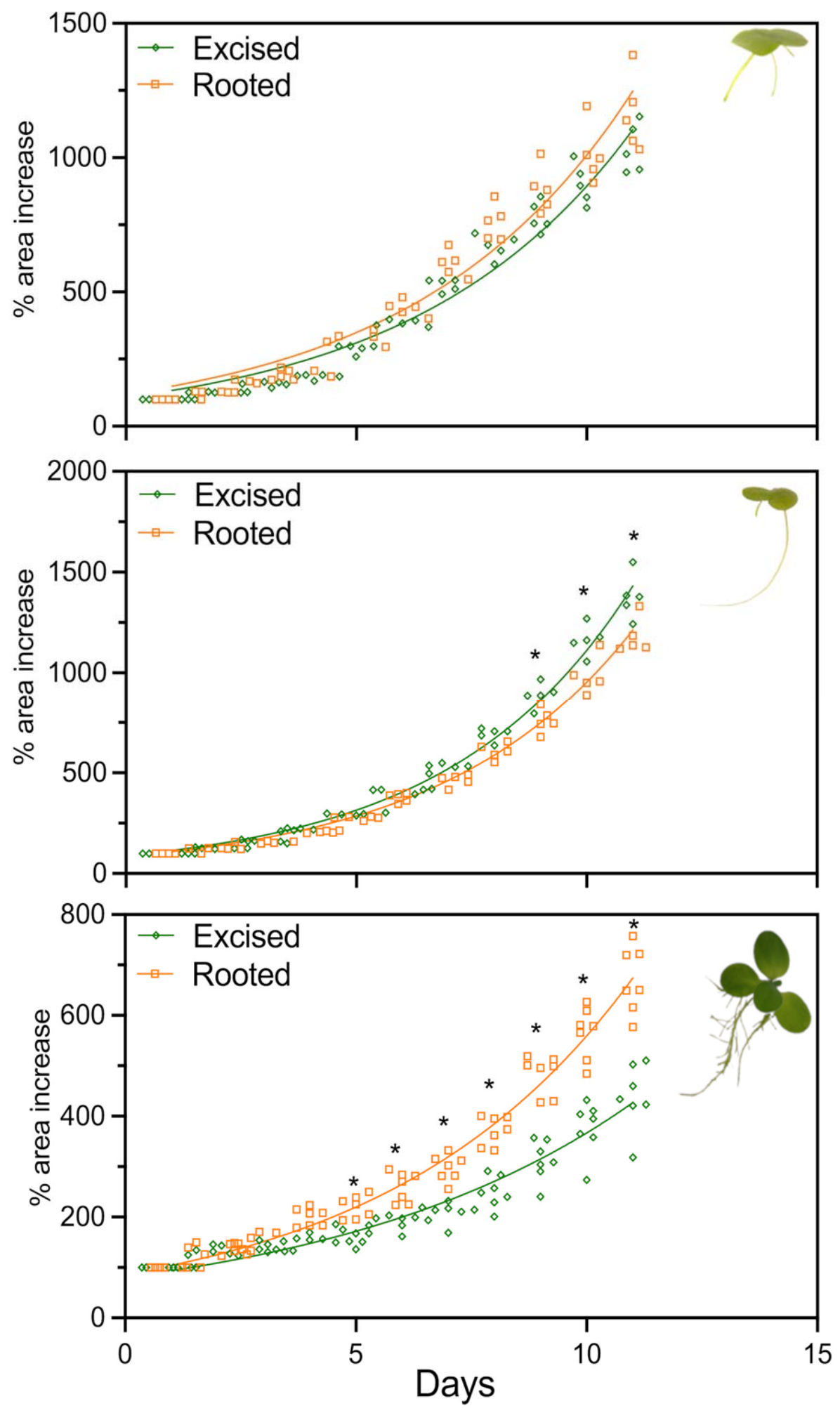

241 concentration in the fronds of both L. minor and S. polyrhiza, and increased Fe, $\mathrm{Zn}$ and $\mathrm{Mn}$ in S.

242 polyrhiza alone. Root removal resulted in a reduction in concentration of $\mathrm{B}$ and $\mathrm{Cu}$ in $\mathrm{L}$. minor alone 


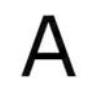

Rooted Vs. Excised
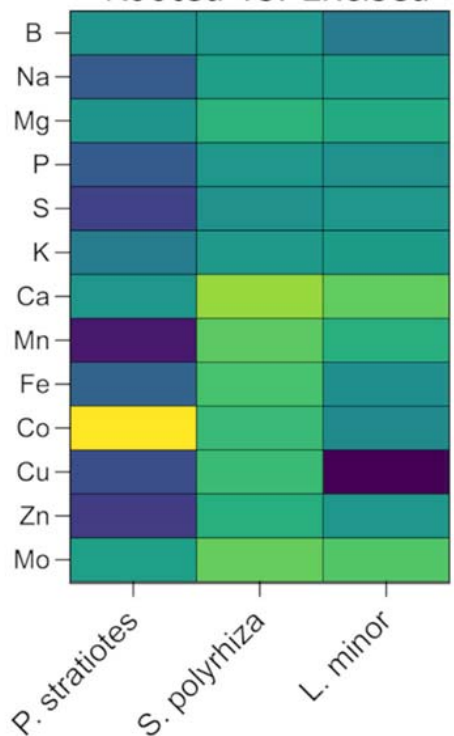

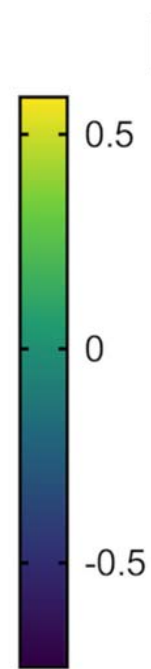

B

\begin{tabular}{cccc}
\hline & P. stratiotes & S. polyrhiza & L. minor \\
\hline $\mathrm{B}$ & - & - & $\downarrow$ \\
\hline $\mathrm{Na}$ & - & - & - \\
\hline $\mathrm{Mg}$ & - & - & - \\
\hline $\mathrm{P}$ & $\downarrow$ & - & - \\
\hline $\mathrm{S}$ & $\downarrow$ & - & - \\
\hline $\mathrm{K}$ & $\downarrow$ & - & - \\
\hline $\mathrm{Ca}$ & - & $\uparrow$ & $\uparrow$ \\
\hline $\mathrm{Mn}$ & $\downarrow$ & $\uparrow$ & - \\
\hline $\mathrm{Fe}$ & $\downarrow$ & $\uparrow$ & - \\
\hline $\mathrm{Co}$ & $\uparrow$ & - & - \\
\hline $\mathrm{Cu}$ & - & - & $\downarrow$ \\
\hline $\mathrm{Zn}$ & $\downarrow$ & $\uparrow$ & - \\
\hline $\mathrm{Mo}$ & - & - & -
\end{tabular}

243 (Figure 6A, B, Supplementary Figure 2). In contrast, the impact of root removal on the ionomic

244 composition of Pistia was considerably greater, with $\mathrm{P}, \mathrm{S}, \mathrm{K}, \mathrm{Fe}, \mathrm{Mn}$ and $\mathrm{Zn}$ all being significantly

245 reduced (Figure 6B, Supplementary Figure 2). Together, these data suggest that whilst roots are no

246 longer required for growth and nutrient uptake in duckweeds, Pistia roots still play an important role

247 in growth and nutrient acquisition. However, given that they are not absolutely required for growth,

248 it may be that Pistia is en route to root vestigiality, albeit at a less advanced stage than the 249 duckweeds.

250

251 


\section{Discussion}

254 Here we sought to better resolve whether the duckweed root may be a vestigial organ, with the aim 255 of clarifying if duckweeds may serve as a helpful model for understanding the molecular 256 mechanisms underpinning organ loss. For an organ to be considered vestigial, it must have lost its 257 salient function. Typically, such organs undergo accompanying reductions in size and complexity. 258 Defining salient functions for an individual organ is challenging. However, it is clear that for almost all angiosperms, a primary function of roots is to supply water and nutrients to the growing plant, sustaining growth of the aboveground tissues (Boyce, 2005). We therefore examined the anatomy, as well as water and nutrient uptake ability, of duckweed roots to better ascertain the position of each species group along a trajectory towards vestigiality, culminating in root loss in the most recently evolved Wolffia and Wolffiella (Fig. 1).

We began by surveying the anatomy of a global collection of specimens including almost all rooted duckweeds, allowing us to observe if a) the reduced anatomy in duckweeds is consistent between species and genera and b) if any trends in root reduction are present at the anatomical level. This built upon previous reports looking into a handful of species (An et al., 2019; Landolt, 1986; Melaragno and Walsh, 1976), expanding it considerably to encompass almost all rooted species of duckweeds. We compared duckweed root morphology with the sister Pistia stratoites, which is believed to have undergone an independent and more recent invasion of the aquatic environment.

272 Our findings revealed that duckweed roots are consistently reduced in both size (diameter) and 273 morphological complexity compared with Pistia, consistent with the idea that they are no longer required for active nutrient transport (Figure 2A, Supplementary Figure 2).

As well as the macroscopic reduction in root system complexity - multiple roots per frond to single root per frond - in Spirodela and Landoltia versus Lemna, we also leveraged our anatomical data to question whether root anatomical complexity reduces concurrently with root number. We observed a reduction in both the number of cortical cell layers and the presence of aerenchyma between

280 Spirodela spp. and Lemna spp. The apparent decrease in complexity between Spirodela spp. and Lemna spp. supports a model in which traits associated with root complexity have been progressively lost in duckweeds as novel species have formed, accompanying the reduction in root number. In comparison, Pistia plants may be less far along this trajectory towards root vestigialization. A PCoA encompassing all root anatomical traits measured further confirmed these observations. Virtually all individuals of the genera Spirodela and Landoltia sit in two distinct clusters 
based on their root anatomy, separated from Lemna individuals, which exist almost exclusively in a single cluster, matching their monophyletic origin. This correlation with phylogenetic groupings further supports the concept that root anatomy has evolved to become further reduced in Lemna. We feel root loss in duckweed presents a unique opportunity for deepening our understanding of vestigiality. In other models of organ loss, such as cavefish, evolution has produced a more binary range of traits (i.e. sighted versus unsighted fish). In comparison the duckweed root offers a greater spectrum of phenotypes in terms of both root number and anatomy, providing a rich pool of germplasm within which we can explore networks controlling discrete aspects of root development.

The anatomy of the duckweed root is also highly similar to that of lateral roots in Pistia. This cellular arrangement is similar to that of fine lateral roots of other monocot species (Watanabe et al., 2020). When root anatomical trait values are mapped onto a PCoA, Pistia lateral roots sit in a cluster which is primarily composed of Lemna spp. It is feasible that this cellular arrangement seen in Lemna represents or is approaching an anatomical 'minimum' without which it would not be possible to form a root.

If duckweed roots are vestigial, they should not only have reduced complexity but will have lost some or all of their salient function. We showed that whilst Pistia roots had a positive and significant effect on leaf growth, growth of duckweed fronds was largely unaffected in rooted versus rootless samples, implying that roots are dispensable for providing nutrients and water for growth. Growth data alone do not provide a full picture of capacity for nutrient transport. We therefore leveraged an ionomics platform that permitted a survey of the elemental landscape of duckweed fronds when grown without a root, which we compared with Pistia stratiotes. We considered a broad suite of nutrients including every element present in our growth media, except nitrogen. We did not see major shifts in the elemental composition of the fronds of either duckweed species when subjected to continuous root removal. Strikingly, no elements included in our analysis ( 0 out of 13 ) exhibited reduced accumulation in Spirodela polyrhiza grown without roots, and only 2 out of 13, B and $\mathrm{Cu}$, did in Lemna minor. Conversely, in Pistia stratiotes, 6 of the 13 elements quantified exhibited reduced accumulation in shoot tissues as a consequence of root removal, including elements critical

315 for growth with well-established root-mediated uptake mechanisms such as P and K. Together, this 316 clearly evidences the dispensability of roots in duckweeds for nutrient uptake. A surprising result in 317 both Spirodela and Lemna was the increase in certain nutrients following root excision. This included $318 \mathrm{Ca}, \mathrm{Fe}, \mathrm{Zn}$, and $\mathrm{Mn}$, with $\mathrm{Ca}$ being consistently elevated. A potential hypothesis is that duckweed roots could be repurposed for the storage or sequestration of nutrients. Raphides (calcium oxalate 
crystals) are present in Lemna minor and have been shown to localise within roots (Franceschi 1987,

321 1989).

323 Considering the definitions of vestigiality by both Prout and Muller, we feel that these data clarify

324 that duckweed roots are indeed vestigial, and to varying degrees across the group, opening the door

325 to their utilisation as models for understanding this vestigiality. This gradient also poses a key

326 question. If duckweed roots are vestigial, why are they maintained in some species? Whilst some

327 vestigial structures may be non-functional, others may have gained novel functions as a

328 consequence of reduced constraint (i.e., exaptation), whilst other structures may be in an

329 intermediate state whereby the transition to vestigiality is incomplete (Walker-Larsen and Harder,

330 2001). It is therefore possible that relaxed selection pressure has permitted duckweed roots to

331 become neofunctionalised to perform novel roles. It has been suggested that duckweed roots may

332 function as organs of stability (Landolt, 1986) or aid dispersal by adhering to animals (Cross, 2017).

333

334 In conclusion, these results support a model of progressive vestigiality of roots across the

335 duckweeds. Broadly it points to a duckweed root that is both anatomically simplified and

336 dispensable for the salient functions of water or nutrient uptake. However, we acknowledge that

337 our experiments do not completely rule out a role for root in nutrient uptake under, for example,

338 limiting conditions or in natural habitats, replete with companion species and competitors. However,

339 these results lay a foundation for the use of duckweed roots as a model system for further

340 investigation into the molecular and evolutionary processes underlying vestigiality in plants. 


\section{Duckweed growth and culture}

347 All duckweed stocks employed in this experiment were obtained from the Landolt collection, ETH

348 Zurich (http://www.duckweed.ch), except for Spirodela polyrhiza lines 9509 and 7948 which were provided by Klaus Appenroth, Friedrich Schiller University, Jena. Four-digit numerical codes following species names refer to their Landolt accession number. Stocks were maintained on liquid $\mathrm{N}$-media or SH-media (Appenroth et al., 1996) at $120 \mu \mathrm{mol} \mathrm{m} \mathrm{m}^{-1}$ light and $16 / 8 \mathrm{~h}$ light cycle in a Conviron growth chamber, set to $22^{\circ} \mathrm{C}$ with $70 \%$ RH. Pistia stratiotes was obtained from JAM Aquatics, Wrexham, UK.

\section{Root cross section anatomy}

356

Plants were grown in $250 \mathrm{ml}$ conical flasks containing $150 \mathrm{ml}$ of liquid $\mathrm{N}$-media in the same conditions as stocks. Flasks were inoculated with 5-10 colonies from the stock collections and grown for 2-6 weeks. Plants selected possessed roots of average or greater length, and fronds of average or greater area based on visual appraisal.

Vibratome sectioning of duckweed roots was conducted as per Jones et al., (2021). For each line, ten individual plants per line were embedded and sectioned, and 5-10 root sections were collected per plant, stained using the method described in Atkinson and Wells (2017), and imaged using confocal laser scanning microscopy. Basic fuchsin staining was conducted at a concentration of $0.01 \%$ following sectioning. A single image section per plant was selected based on quality and representation, then measured using FIJI (Schindelin et al., 2012). Cells were classified into layers in concentric rings from the endodermis outwards. The diameter of each layer was measured, as was the number of cells in each layer, along with the diameter of the endodermis, number of endodermal cells, and number of cells in the stele. Diameters were measured using the ruler tool. At each layer, diameter was measured from 5 points around the circumference of the layer, measuring the maximum distance between points on the layer, then the mean was taken of these 5 points for each layer. Epidermal cells had poor dye penetration, and a reduced fluorescence on the confocal microscope, and so could not be reliably counted.

375 
378 For the root removal experiment, plants were grown in Schenck-Hildebrandt (SH) media. For the 379 control treatment, no manipulation was undertaken. In the root removal treatment, all visible roots 380 were removed from colonies daily using ethanol sterilised surgical scissors. For Spirodela polyrhiza 381 and Lemna minor, each treatment consisted of five individual flasks, each seeded with 3 colonies 382 onto $100 \mathrm{ml}$ of media. Individual flasks were treated as a replicate and flasks were arranged randomly in the growth cabinet and re-randomized daily. For Pistia stratiotes, each flask was seeded with a young individual plant with 3 emerged leaves visible to the naked eye, to a total of 7 plants/treatment. The treatment regimen was conducted for 11 consecutive days.

Plants were imaged daily in their flasks from beneath, utilising a transparent raised platform featuring a water bath in which to place the flasks to correct for the optical distortion. Images were processed using FIJI to measure frond or aerial tissue area. For duckweed flasks, RGB images were split into their constitutive 8-bit channels, and the blue channel retained. Frond tissues alone were then selected using the threshold tool and area measured. For Pistia, images were again split, but the red channel retained. This was then subject to gaussian blur (sigma $=7.0$ ) and again only the aerial tissues selected using the threshold tool. In rooted samples where this alone was not sufficient to separate frond and root, the select polygons tool was used to exclude any additional root captured by thresholding.

\section{Ionomic analysis}

Samples were harvested immediately following the root removal experiment. Prior to harvesting, roots were removed from fronds or aerial tissues and washed 3 times for 2 minutes with MilliQ water. Samples were placed in pre-weighed Pyrex test tubes, and dried at $88^{\circ} \mathrm{C}$ for $24 \mathrm{~h}$. Then, dry weight was recorded, and $1 \mathrm{ml}$ concentrated trace metal grade nitric acid Primar Plus (Fisher Chemicals) spiked with in internal standard was added to the samples that were further digested in DigiPREP MS dry block heaters (SCP Science; QMX Laboratories) for 4 hours at $115^{\circ} \mathrm{C}$ following the method adapted from Danku et al.,2013. After digestion, samples were diluted to $10 \mathrm{~mL}$ with 18.2 $\mathrm{M} \Omega \mathrm{cm}$ Milli-Q Direct water and elemental analysis was performed using an ICP-MS, PerkinElmer NexION 2000 and twenty-three elements were monitored (Li, B, Na, Mg, P, S, K, Ca, Ti, Cr, Mn, Fe,

$408 \mathrm{Co}, \mathrm{Ni}, \mathrm{Cu}, \mathrm{Zn}, \mathrm{As}, \mathrm{Se}, \mathrm{Rb}, \mathrm{Sr}, \mathrm{Mo}, \mathrm{Cd}$ and $\mathrm{Pb}$ ). To correct for variation within ICP-MS analysis run, 409 liquid reference material was prepared using pooled digested samples, and run after every nine 
411 instrument software. Further data processing including calculation of final elements concentrations

412 was performed in Microsoft Excel.

413

\section{Statistical analyses}

415

416 All statistical analyses were conducted in GraphPad Prism version 9.0 (graphpad.com). For the 417 anatomical dataset, principal coordinates analysis was conducted on 19 variables and 210 rows 418 utilising parallel analysis with 1000 simulations and a random seed. For root removal experiments, 419 two-way repeated measures ANOVA was performed, followed with Sidaks' multiple comparisons 420 test to establish differences in growth on a per-day basis. For nutrient concentration comparisons 421 generated by ionomic analyses, data were compared with one-way ANOVA followed by Sidak's 422 multiple comparison's test to establish differences in concentration between individual nutrients. 423 Log2 fold changes generated from ionomic data were calculated as Log2(elemental conc. roots 424 removed)-Log2(elemental conc. rooted).

425

\section{Figure legends}

427

428 Figure 1. Representative phylogeny of the duckweed genera and Pistia highlighting the progressive 429 loss of roots of roots and loss of individual root traits as genera diverge (indicated by + and -; arrows 430 next to cortical cell layers indicate the progressive reduction in layer number as the genera diverge) 431 (after Tippery and Les, 2020). Representative images (not to scale) of species from each genera are 432 shown for illustrative purposes.

433

Figure 2. Comparison of root anatomical traits across almost all extant duckweeds reveals a highly reduced anatomy. A) Representative images of root sections from species representing each duckweed genera and mainand lateral roots of Pistia stratiotes. Images were obtained via fresh

437 tissue sectioning and confocal imaging. Scale bar $=50 \mu \mathrm{M}$ for entire roots; $10 \mu \mathrm{M}$ for vasculature 438 close-up. B) Rose diagram displaying the width of each cell layer $(\mu \mathrm{m})$ for roots of 20 duckweed lines 439 encompassing 13 species, denoted at the outside of the circle. C) Rose diagram displaying the 440 number of cells in cell layer for roots of the aforementioned lines, denoted at the outside of the 441 circle, with $P$. stratiotes main roots (D) in a separate bar chart for ease of resolution. Background 442 colour underlying the species labels represents genera; yellow represents Pistia, purple Spirodela, 443 pink Landoltia, green Lemna. E) Colour coded key to the different cell layers displayed on the rose 
444 diagrams. CCL stands for cortical cell layer. $n=10$ root sections derived from different plants, except

445 for Pistia stratiotes (main) and L. trisulca where $n=5$ root sections derived from individual plants.

446

447 Figure 3. Basic fuchsin staining of duckweed vasculature highlights lignification in the endodermis 448 and central xylem. Entire root section and accompanying close up of the vasculature of Spirodela 449 polyrhiza 9509 with cell wall staining (calcofluor white; green) and lignin staining (0.01\% Basic 450 Fuchsin; magenta). Scale bar $=50 \mu \mathrm{M}$ for entire roots; $10 \mu \mathrm{M}$ for vasculature close-up.

451

452 Figure 4. Principal coordinates analysis of duckweed anatomical traits highlights interspecies 453 differences and a gradient of reducing root anatomical complexity. A) PCoA based on 21 454 components, with 210 rows, derived from an anatomical analysis of fresh root sections from 20 455 duckweed lines, encompassing 13 species, and main and lateral roots of Pistia stratiotes. Clusters 456 have been manually highlighted and numbered for ease of further discussion. Percentage of 457 variance explained by each PC is indicated on the relevant axis. B) Summary of the 19 variables used to generate the PCoA in A.

459

460 Figure 5. Growth of the duckweeds Spirodela polyrhiza and Lemna minor is not impacted by 461 continual root removal, unlike the aroid Pistia stratiotes. Plants were subjected to continuous root 462 removal and growth compared to untreated controls. Growth was measured as area of fronds (or 463 aerial tissues for Pistia), derived from daily imaging from beneath, and plotted as a percentage 464 increase relative to the initial (day 1) area value. Lines show the best fit of an exponential growth 465 curve. A) Spirodela polyrhiza; B) Lemna minor; C) Pistia stratiotes. $n=5$ flasks, each initially seeded 466 with 3 colonies for duckweeds; $n=7$ flasks, each initially seeded with 1 plant for Pistia. Asterisks

467 show statistically significant differences as assessed by two-way repeated measures ANOVA 468 followed by Sidak's multiple comparisons. Lines show the best fit of an exponential (Malthusian) 469 growth curve.

470

471 Figure 6. Continuous root removal has a limited effect on element accumulation on the duckweeds 472 Spirodela polyrhiza and Lemna minor but reduces the accumulation of a number of elements in the 473 aroid Pistia stratiotes. A) Heatmap showing the log2 fold change of rooted versus rooted elements 474 for each species. B) Table synthesising the data generated in A) indicating whether root removal 475 results in statistically significant increased accumulation (green upwards arrow), decreased 476 accumulation (red downwards arrow), or no significant change (blue hyphen). Significance $(P<0.05)$ 477 was determined by one-way ANOVA followed by Sidak's multiple comparisons test. $n=5$ flasks, each 
bioRxiv preprint doi: https://doi.org/10.1101/2022.01.05.475062; this version posted January 7, 2022. The copyright holder for this preprint

(which was not certified by peer review) is the author/funder, who has granted bioRxiv a license to display the preprint in perpetuity. It is made available under aCC-BY-NC-ND 4.0 International license.

478 initially seeded with 3 colonies for duckweeds; $n=7$ flasks, each initially seeded with 1 plant for 479 Pistia.

480

481 


\section{Parsed Citations} available under aCC-BY-NC-ND 4.0 International license.

Acosta, K., Appenroth, K., Borisjuk, L., Edelman, M., Heinig, U., Jansen, M., Oyama, T., Pasaribu, B., Schubert, I., Sorrels, S., Sree, K., Xu, S., Michael, T. and Lam, E., 2021. Return of the Lemnaceae: duckweed as a model plant system in the genomics and postgenomics era. The Plant Cell, 33(10), pp.3207-3234

Google Scholar: Author Only Title Only Author and Title

An, D., Zhou, Y., Li, C., Xiao, Q., Wang, T., Zhang, Y., Wu, Y., Li, Y., Chao, D.Y., Messing, J. and Wang, W., 2019. Plant evolution and environmental adaptation unveiled by long-read whole-genome sequencing of Spirodela. Proceedings of the National Academy of Sciences, 116(38), pp.18893-18899.

Google Scholar: Author Only Title Only Author and Title

Atkinson, J.A and Wells, D.M., 2017. An updated protocol for high throughput plant tissue sectioning. Frontiers in plant science, 8, p.1721.

Google Scholar: Author Only Title Only Author and Title

Boyce, C.K., 2005. The evolutionary history of roots and leaves. In Vascular transport in plants (pp. 479-499). Academic Press. Google Scholar: Author Only Title Only Author and Title

Bog, M., Sree, K.S., Fuchs, J., Hoang, P.T., Schubert, I., Kuever, J., Rabenstein, A, Paolacci, S., Jansen, M.A and Appenroth, K.J., 2020. A taxonomic revision of Lemna sect. Uninerves (Lemnaceae). Taxon, 69(1), pp.56-66.

Google Scholar: Author Only Title Only Author and Title

Cabrera, L.I., Salazar, G.A, Chase, M.W., Mayo, S.J., Bogner, J. and Dávila, P., 2008. Phylogenetic relationships of aroids and duckweeds (Araceae) inferred from coding and noncoding plastid DNA American Journal of Botany, 95(9), pp.1153-1165.

Google Scholar: Author Only Title Only Author and Title

Cedergreen, N. and Madsen, T.V., 2002. Nitrogen uptake by the floating macrophyte Lemna minor. New phytologist, 155(2), pp.285-292.

Google Scholar: Author Only Title Only Author and Title

Cross, 2017. Duckweed Roots: their role in vegetative dispersal. Duckweed Forum, 5(3), pp. 58-59

Google Scholar: Author Only Title Only Author and Title

Echlin, P., Lai, C. and Hayes, T.L., 1981. The distribution and relative concentration of potassium in the root-tips of Lemna minor L. analysed by low-temperature X-ray microanalysis. Scanning Electron Microscope (USA), pp. 489-498.

Google Scholar: Author Only Title Only Author and Title

Fang, Y.Y., Babourina, O., Rengel, Z, Yang, X.E. and Pu, P.M., 2007. Ammonium and nitrate uptake by the floating plant Landoltia punctata. Annals of botany, 99(2), pp.365-370.

Google Scholar: Author Only Title Only Author and Title

Fong, D., Kane, T. and Culver, D., 1995. Vestigialization and Loss of Nonfunctional Characters. Annual Review of Ecology and Systematics, 26(1), pp.249-268.

Google Scholar: Author Only Title Only Author and Title

Friis, E.M., Pedersen, K.R. and Crane, P.R., 2004. Araceae from the Early Cretaceous of Portugal: evidence on the emergence of monocotyledons. Proceedings of the National Academy of Sciences, 101(47), pp.16565-16570.

Google Scholar: Author Only Title Only Author and Title

Franceschi, V.R., 1989. Calcium oxalate formation is a rapid and reversible process in Lemna minor L. Protoplasma, 148(2), pp.130-137.

Google Scholar: Author Only Title Only Author and Title

Franceschi, V.R., 1987. Oxalic acid metabolism and calcium oxalate formation in Lemna minor L. Plant, Cell \& Environment, 10(5), pp.397-406.

Google Scholar: Author Only Title Only Author and Title

Gorham, P.R., 1941. Measurement of the response of Lemna to growth promoting substances. American Journal of Botany, pp.98101.

Google Scholar: Author Only Title Only Author and Title

Hegelmaier, F 1868. Die Lemnaceen - eine monographische Untersuchung. 169 pp. XV plates. Wilhelm Engelmann, Leipzig.

Google Scholar: Author Only Title Only Author and Title

Jung, J., Lee, S.C. and Choi, H.K., 2008. Anatomical patterns of aerenchyma in aquatic and wetland plants. Journal of Plant

Biology, 51(6), pp.428-439.

Google Scholar: Author Only Title Only Author and Title

Kim, I., 2007. Development of the root system in Spirodela polyrhiza (L.) Schleiden (Lemnaceae). Journal of Plant Biology, 50(5), 
pp.540-547. available under aCC-BY-NC-ND 4.0 International license.

Google Scholar: Author Only Title Only Author and Title

Knobloch, I., 1951. Are There Vestigial Structures in Plants?. Science, 113(2938), pp.465-465.

Landolt, E., 1998. Anatomy of the Lemnaceae (duckweeds), In Extreme Adaptations in Angiospermous Hydrophytes. (pp. 1-127.). Borntraeger, Berlin.

Google Scholar: Author Only Title Only Author and Title

Landolt, E. 1986. The family of Lemnaceae - a monographic study, Vol 1.. Veroff. Geobot. Inst. ETH, Stiftung Rubel. No. 71. Google Scholar: Author Only Title Only Author and Title

Les, D.H., Crawford, D.J., Landolt, E., Gabel, J.D. and Kimball, R.T., 2002. Phylogeny and systematics of Lemnaceae, the duckweed family. Systematic Botany, 27(2), pp.221-240.

Google Scholar: Author Only Title Only Author and Title

Melaragno, J.E. and Walsh, M.A, 1976. Ultrastructural features of developing sieve elements in Lemna minor L.-the protoplast. American Journal of Botany, 63(8), pp.1145-1157.

Google Scholar: Author Only Title Only Author and Title

Muhonen M.I., Showman J.O., Couch R.I., 1983. Nutrient absorption by Spirodela polyrrhiza. Journal of Aquatic Plant

Management, 21(2), pp.107-109.

Google Scholar: Author Only Title Only Author and Title

Prout, T., 1964. Observations on Structural Reduction in Evolution. The American Naturalist, 98(901), pp.239-249.

Google Scholar: Author Only Title Only Author and Title

Schindelin, J., Arganda-Carreras, I., Frise, E., Kaynig, V., Longair, M., Pietzsch, T., Preibisch, S., Rueden, C., Saalfeld, S., Schmid,

B. and Tinevez, J.Y., 2012. Fiji: an open-source platform for biological-image analysis. Nature methods, 9(7), pp.676-682.

Google Scholar: Author Only Title Only Author and Title

Sherman, T., Bowling, A, Barger, T. and Vaughn, K., 2008. The Vestigial Root of Dodder (Cuscuta pentagona) Seedlings. International Journal of Plant Sciences, 169(8), pp.998-1012.

Google Scholar: Author Only Title Only Author and Title

Steiner, K.E., 1998. The evolution of beetle pollination in a South African orchid. American Journal of Botany, 85(8), pp.1180-1193. Google Scholar: Author Only Title Only Author and Title

Stockey, R.A, Hoffman, G.L. and Rothwell, G.W., 1997. The fossil monocot Limnobiophyllum scutatum: resolving the phylogeny of Lemnaceae. American Journal of Botany, 84(3), pp.355-368.

Google Scholar: Author Only Title Only Author and Title

Tippery, N.P. and Les, D.H., 2020. Tiny plants with enormous potential: phylogeny and evolution of duckweeds. In The Duckweed Genomes (pp. 19-38). Springer, Cham

Google Scholar: Author Only Title Only Author and Title

Vu, G.T., Fourounjian, P., Wang, W. and Cao, X.H., 2020. Future prospects of duckweed research and applications. The Duckweed Genomes, pp.179-185.

Google Scholar: Author Only Title Only Author and Title

Walker-Larsen, J. and Harder, L., 2001. Vestigial organs as opportunities for functional innovation: the example of the penstemon staminode. Evolution, 55(3), p.477.

Google Scholar: Author Only Title Only Author and Title

Watanabe, Y., Kabuki, T., Kakehashi, T., Kano-Nakata, M., Mitsuya, S. and Yamauchi, A, 2020. Morphological and histological differences among three types of component roots and their differential contribution to water uptake in the rice root system Plant Production Science, 23(2), pp.191-201.

Google Scholar: Author Only Title Only Author and Title

Wilde, V., Kvaček, Z and Bogner, J., 2005. Fossil leaves of the Araceae from the European Eocene and notes on other aroid fossils. International Journal of Plant Sciences, 166(1), pp.157-183.

Google Scholar: Author Only Title Only Author and Title

Yamamoto, Y., Stock, D. and Jeffery, W., 2004. Hedgehog signalling controls eye degeneration in blind cavefish. Nature, 431(7010), pp.844-847.

Yang, J., Li, G., Hu, S., Bishopp, A, Heenatigala, P., Kumar, S., Duan, P., Yao, L. and Hou, H., 2018. A protocol for efficient callus induction and stable transformation of Spirodela polyrhiza (L.) Schleiden using Agrobacterium tumefaciens. Aquatic Botany, 151, pp.80-86.

Google Scholar: Author Only Title Only Author and Title 